\title{
Supply Interruption Supply Chain Network Model with Uncertain Demand: An Application of Chance-Constrained Programming with Fuzzy Parameters
}

\author{
Haidong Guo $\mathbb{i},^{1,2}$ Shengyu Wang $\mathbb{i D}^{3}{ }^{3}$ and Yu Zhang $\mathbb{i D}^{4}$ \\ ${ }^{1}$ School of Economics, Zhejiang University of Technology, Hangzhou 310023, China \\ ${ }^{2}$ College of Education, Zhejiang University of Technology, Hangzhou 310023, China \\ ${ }^{3}$ School of Finance and Trade, Wenzhou Business College, Wenzhou 325035, Zhejiang, China \\ ${ }^{4}$ Department of Media and Communications, London School of Economics and Political Science, London, UK
}

Correspondence should be addressed to Haidong Guo; haidongguo1976@163.com

Received 19 November 2020; Revised 27 December 2020; Accepted 17 January 2021; Published 8 February 2021

Academic Editor: Stefania Tomasiello

Copyright ( 92021 Haidong Guo et al. This is an open access article distributed under the Creative Commons Attribution License, which permits unrestricted use, distribution, and reproduction in any medium, provided the original work is properly cited.

The downstream supply interruption of manufacturers is a disaster for the company when the demand is uncertain in the market; a fuzzy programming with fuzzy parameters model of supply interruption supply chain network is established by simulating market operation rules. The aim of the current study is to build a fuzzy chance-constrained programming method which is developed for supporting the uncertainty of demand. This method ensured that the fuzzy constraints can be satisfied at specified confidence levels, leading to cost-effective solutions under acceptable risk magnitudes. Finally, through the case of the electronic product manufacturing enterprise, the feasibility and effectiveness of the proposed model are verified by adopting a sensitivity analysis of capacity loss level and minimizing objective function. Numerical simulation shows that selecting two manufacturing centers can effectively reduce the supply chain cost and maintain business continuity.

\section{Introduction}

In the actual production process, the uncertainty of demand caused by the individualization and diversity requirements of consumers often impacts the productivity of manufacturers [1-3]. According to the Japan Economic Daily, Foxconn's original 60 iPhone XR production lines, in November 2018, due to insights into changes in product demand in the market, 45 production lines were decided to start and the remaining 15 production lines were suspended indefinitely because the manufacturer's production line usually changed according to user demand. This crisis is manifested in the risk of disruption to the supply capacity of the end customer. For example, in 2019, Xiao Mi's new mobile phone Xiaomi 9 was sold out in a minute after the release of Jing Dong due to insufficient stocking, which seriously affected the profit of Xiaomi enterprises. The Vivo IQOO mobile phone is also popular, but the supply is sufficient, effectively avoiding the risk of supply interruption. Analysis of the underlying causes shows that the reliability of the manufacturing centers of the two companies is the main source of the supply disruption crisis. Among them, Xiaomi Company is organized by Foxconn and Inventec Appliances Corp. Foundry companies have their own interests, usually not only for Xiaomi's enterprises, but also preferentially produce orders with large profits, so there will be a risk of disruption of Xiaomi's mobile phone supply. The Vivo Company has four production bases in Dongguan, Chongqing, New Delhi, India, and Jakarta, Indonesia. 122 modern production lines can produce 10 million mobile phones per month, and the manufacturing center of Vivo is dedicated to the production of Vivo mobile phones and service, thus providing a stable source of supply for mobile phone sales.

The solution to supply disruption is usually to form different supply chain risk management models based on the 
analysis of the company's competitive strategy [4-6]. Because the supply chain flexible design can effectively solve the integration of market and enterprise, it is of great significance to deal with potential supply chain risks [7]. Often, the company's flexible design of the supply chain after determining its strategic target market requires attention to two main characteristics: supply chain scope (local or global) and competitive priority (responsiveness or cost reduction) [8-10]. At this stage, it is important to understand the supply chain vulnerability caused by supply disruptions, which will help to achieve a dynamic adaptive elastic supply chain. Figure 1 illustrates the dynamic process of supply chain resiliency design in this paper and demonstrates the optimization process of supply chain risk management to alleviate supply chain risk. This process is mainly achieved through supply chain resiliency design [11-14].

At present, the research on the risk of supply interruption is rich, mainly including multisupplier strategy research [15-17]; the establishment of emergency inventory $[18,19]$; alternative suppliers $[20,21]$; contract theory to reduce futures commodity risks [22]; [23-25]. Facility safety is improved to cope with the supply disruption crisis caused by natural risks [26,27], but the above research usually lacks a flexible mechanism and cannot respond to supply disruption crisis according to supply chain structure adjustment and different situational flexibility change strategies [28-31]. However, research methods for uncertainty requirements include the use of fuzzy programming or robust optimization to deal with uncertainty, but these methods usually require a large number of samples, but in fact, the number of samples is limited and only can get the range of sample values rather than the exact value $[8,32,33]$.

Therefore, this paper constructs a three-tier supply chain network model, consisting of one supplier, multiple manufacturers, multiple customers, and a manufacturing company and studies the risk of supply disruption when demand is uncertain [34-40]. The fuzzy number of uncertain demand is converted into the determined risk of supply interruption risk, and the logistics supply is used to coordinate the supply capacity of reliable and unreliable manufacturing centers for supply chain flexibility design, to meet the needs of users while maintaining the stability of the supply chain and reducing the risk of supply [41-45].

\section{Model Assumptions and Construction}

2.1. Description of the Problem. A three-tier supply chain network of suppliers, multiple manufacturers, and multipleend customers, is built as the demand is uncertain, as shown in Figure 2. Assume that the parts in the market are supplied by one supplier, and the manufacturing center organizes the production according to the customer's needs. The reliable manufacturing center produces according to its production capacity to meet the needs of customers. The unreliable manufacturer can adjust the production plan according to its interests and may not meet the needs of the customer. This means that the quantity of products provided by reliable manufacturing centers is stable, while the quantity of products provided by unreliable manufacturers is unstable.
The quantity of products required, and the shortage can be met by the reliable manufacturing center through the coordination of logistics functions from the reliable manufacturing center.

Figure 2 shows two manufacturing centers, which are two types of manufacturing centers. In a supply chain, each type can have multiple manufacturing centers. Among them, the manufacturing center cannot exceed the maximum production capacity of the customer, and the supplier's supply capacity and the production capacity of the manufacturing center are all certain values; the coordination of transportation products between the manufacturing centers does not affect the customer's needs. The location and number of the center are known; each customer only picks up one center for delivery, the reliable manufacturing center does not interrupt, the unreliable manufacturing center will interrupt with a certain probability, and some of the supply capacity will be lost when the interruption occurs, but which can be complemented by a reliable manufacturing center.

\subsection{Symbols and Meanings}

\subsubsection{Collection Definition}

I: reliable production center number, $i \in I$

$J$ : unreliable manufacturing center number, $j \in J$

$L$ : all manufacturing center numbers, $l \in L$ 且 $L \in(I \cup J)$

$K$ : customer point number, $k \in K$

\subsubsection{Parameter Definition}

$\otimes d_{k}$ : fuzzy demand for the $k$ th customer

$d_{a b}$ : transportation cost from manufacturing center $a$ to manufacturing center $b$ or customer

$d_{p i}$ : unit transportation cost from supplier to reliable manufacturing center

$d_{p j}$ : unit transportation cost from supplier to unreliable manufacturing center

$\gamma_{1}$ : manufacturing center 1 distribution capacity

$C R_{i}$ : start-up cost of a reliable manufacturing center

$C R_{j}$ : the cost of starting an unreliable manufacturing center

$q j$ : unreliable distribution center $j$

$p j$ : loss ratio of capacity after unreliable distribution center $j$ interruption

\subsubsection{Decision Variables}

$U_{i}$ : supplier flow to manufacturing center $i$

$U_{j}$ : supplier flow to manufacturing center $j$

$F R_{i k}$ : reliable manufacturing center to customer $k$ 


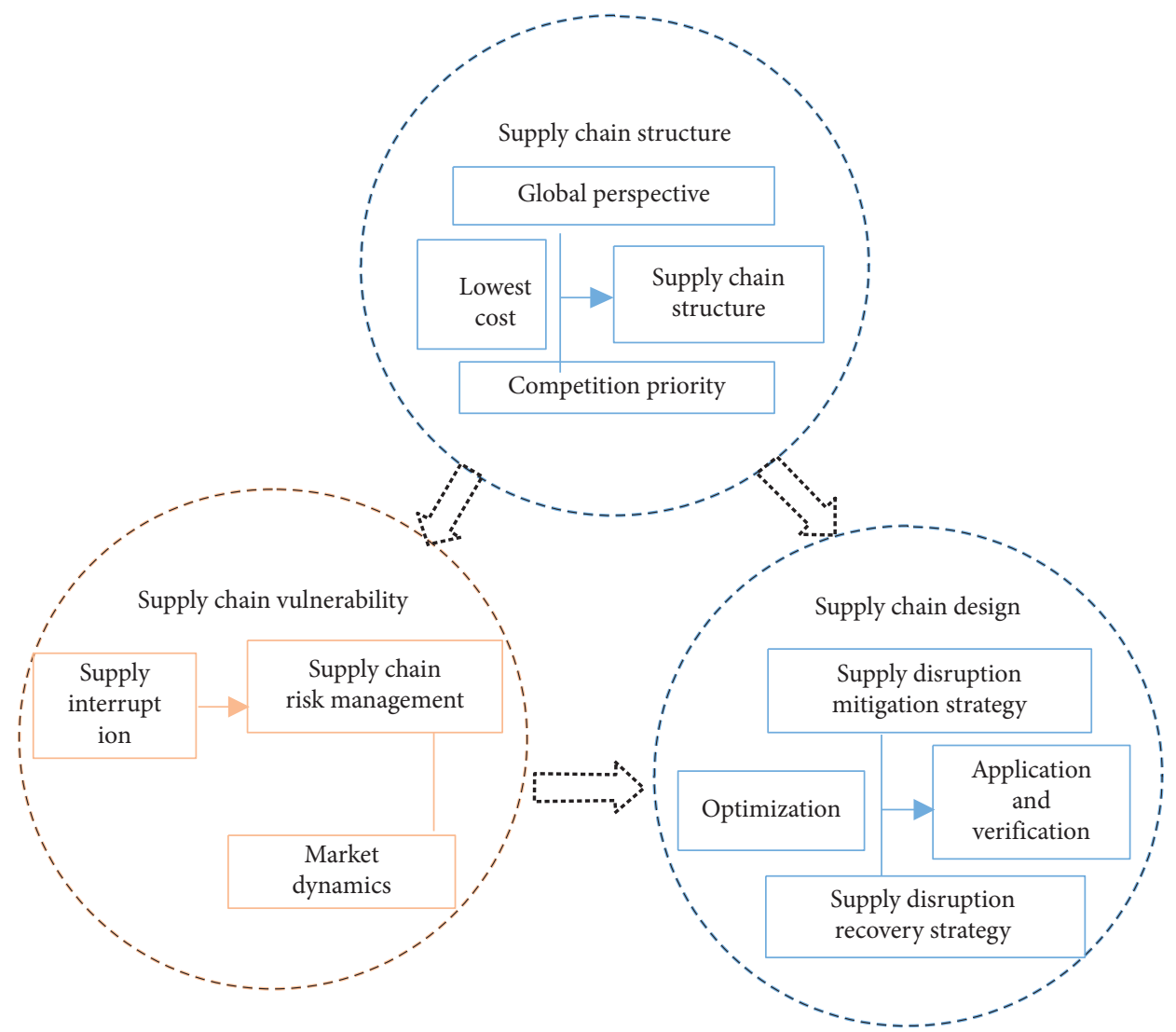

FIgURE 1: Dynamically built supply chain flexibility concept map.

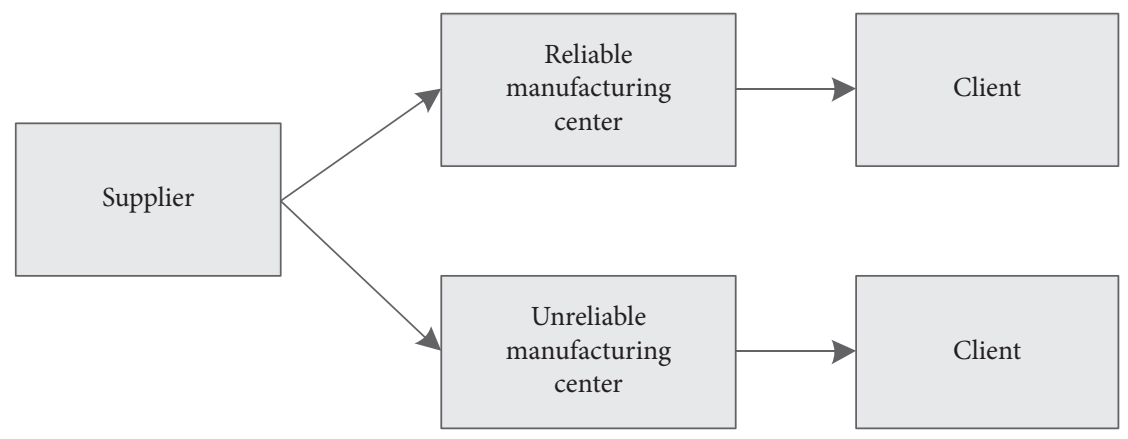

FIGURE 2: Three-level global supply chain network structure.

$F U_{j k}$ : unreliable manufacturing center to customer $k$ $T_{i j}$ : the number of deliveries from the reliable manufacturing center $i$ to the unreliable manufacturing center $j$ after the interruption occurred

$Y R_{i}$ : binary variable, 1 means reliable manufacturing center open; otherwise, 0

$Y U_{j}$ : binary variable, 1 means unreliable manufacturing center open; otherwise, 0

$A R_{i k}$ : binary variable, 1 represents the customer assigned to a reliable manufacturing center; otherwise, 0

$A U_{j k}$ : binary variable, 1 represents the customer assigned to the unreliable manufacturing center; otherwise, 0

\subsection{Mathematical Modelling}

$$
\begin{aligned}
& \min \sum_{i} C R_{i} Y R_{i}+\sum_{j} C U_{j} Y U_{j}+\sum_{i} U_{i} d_{p i}+\sum_{j} U_{j} d_{p j} \\
& \quad+\sum_{i} \sum_{k} \otimes d_{k} A R_{i k} d_{i k}+\sum_{j} \sum_{k} \otimes d_{k} A U_{j k} d_{j k} \\
& \quad+\sum_{i} \sum_{j} q_{j} T_{i j} d_{i j},
\end{aligned}
$$

s.t. $\sum_{i} A R_{i k}+\sum_{j} A U_{j k}=1, \quad \forall k \in K$,

$$
Y R_{l}+Y U_{l} \leq 1, \quad \forall l \in L,
$$




$$
\begin{aligned}
& \sum_{i} Y R_{i} \geq 1 \\
& A R_{i k} \leq Y R_{i} \\
& A U_{j k} \leq Y U_{j} \\
& \sum_{j} F U_{j k} \bullet A U_{j k} \leq T_{i j}+\left(1-p_{j}\right) \bullet \gamma_{j} Y U_{j}, \\
& T_{i j}+\left(1-p_{j}\right) \bullet \gamma_{j} Y U_{j} \leq \gamma_{j} Y U_{j}, \\
& \sum_{k} F U_{j k} \bullet A U_{j k} \geq \sum_{k} \otimes d_{k} \bullet A U_{j k}, \\
& \sum_{k} F U_{i k} \bullet A U_{i k} \geq \sum_{k} \otimes d_{k} \bullet A U_{i k}, \\
& Y R_{i}, Y U_{j}, A R_{i k}, A U_{j k} \in\{0,1\} .
\end{aligned}
$$

Among them, formula (1) is an objective function, which indicates the start-up cost of the manufacturing center, the transportation cost between the facilities, and the transshipment cost from the reliable manufacturing center to the unreliable manufacturing center, with the goal of minimizing the total cost. The constraint condition (2) indicates that a customer can only be assigned to one manufacturing center to meet the demand; formula (3) indicates that only one reliable manufacturing center or unreliable manufacturing center can be constructed at one location; and (4) indicates at least one reliable manufacturing center; formulas (5) and (6) indicates that the customer is assigned to a reliable manufacturing center or an unreliable manufacturing center; formulas (7) and (8) indicate that the flow rate of the material flowing out in the unreliable distribution center is not greater than the sum of the inflow amount and the amount of the inflow. And, less than its production capacity, equations (9) and (10) indicate that customer requirements should all be satisfied; equation (11) represents the value range constraint of the control variables.

2.4. Conversion of Fuzzy Constraints. The objective function in the above model contains uncertain parameters, and it is difficult to solve. Therefore, according to the random chance-constrained programming method in the uncertainty theory proposed by Liu and its followers $[46,47]$, the fuzzy number model with the customer's uncertain demand is transformed into a deterministic model. The fuzzy demand for the customer $\otimes d_{k}$ is expressed as a triangular fuzzy number $\left(d_{j 1}, d_{j 2}, d_{j 3}\right)$. The customer demand function $\mu_{\otimes d_{k}}(x)$ can be expressed as

$$
\mu_{\otimes d_{k}}(x)= \begin{cases}\frac{x-d_{j 1}}{d_{j 2}-d_{j 1}}, & \text { when } d_{j 1} \leq x \leq d_{j 2}, \\ \frac{x-d_{j 3}}{d_{j 2}-d_{j 3}}, & \text { when } d_{j 2} \leq x \leq d_{j 3}, \\ 0, & \text { otherwise. }\end{cases}
$$

For a given confidence level $\theta(0 \leq \theta \leq 1)$, according to the equivalence theorem in the stochastic chanceconstrained programming, $d_{k}$ can be obtained if and only if the following conditions are met:

$$
\left\{\begin{array}{l}
d_{k} \geq(1-\theta) d_{j 1}+\theta d_{j 2} \\
d_{k} \leq(1-\theta) d_{j 2}+\theta d_{j 3}
\end{array}\right.
$$

\section{Case Analysis}

For an electronic product manufacturing enterprise, due to business development needs, the manufacturing center is deployed in the world for the production of electronic products. The manufacturing center is divided into two categories. One is a reliable manufacturing center, which is invested by itself. The production capacity of the manufacturing center will not be interrupted because of the uncertainty of demand and the output produced by it is stable. The other type is entrusted to other enterprises to process. This category is an unreliable manufacturing center. The production capacity of the manufacturing center will be adjusted due to the interests of the processing enterprise itself. Suppose that there is one supplier, four manufacturing centers (including reliable manufacturing centers and unreliable manufacturing centers), and six end customers. The confidence level of customer demand uncertainty is $\theta=0.8$, assuming an outage probability of 0.15 , and the capacity loss ratio of an unreliable manufacturing center is 0.3 . The other parameters are listed in Table 1.

Substitute the parameters into the model and solve them with MATLAB software. The results are shown in Table 2.

As can be seen from Table 2, the objective function is 115,586 yuan, of which the manufacturing center with the opening numbers 1,3 , and 4 is a reliable manufacturing center invested and built by electronic product manufacturing enterprises, and the manufacturing center numbered 2 is entrusted to other enterprises for processing by electronic product manufacturing enterprises, which is an unreliable manufacturing center. The total cost of starting a reliable manufacturing center and an unreliable manufacturing center is 102,139 yuan, the transportation cost is 13,397 yuan, and the transportation cost is 65 yuan. The transfer volume of the reliable manufacturing center 3 to 
TABle 1: Partial parameter range table.

\begin{tabular}{lccc}
\hline Parameter & Range & Parameter & Range \\
\hline$\gamma_{i}$ & Uniform $(300,520)$ & $C U_{j}$ & Uniform (18000, 26000) \\
$\theta$ & 0.8 & $C R_{i}$ & Uniform (21600, 31200) \\
$d_{a b}$ & $(1,6,11)$ & - & - \\
\hline
\end{tabular}

TABLe 2: Results of the study.

\begin{tabular}{lccccc}
\hline Objective function value & Manufacturing center cost & Transportation cost & Transshipment cost & $Y R_{i}$ & $Y U_{i}$ \\
\hline 115,585 & 102,139 & 13,381 & 65 & $1,3,4$ & 2 \\
\hline
\end{tabular}

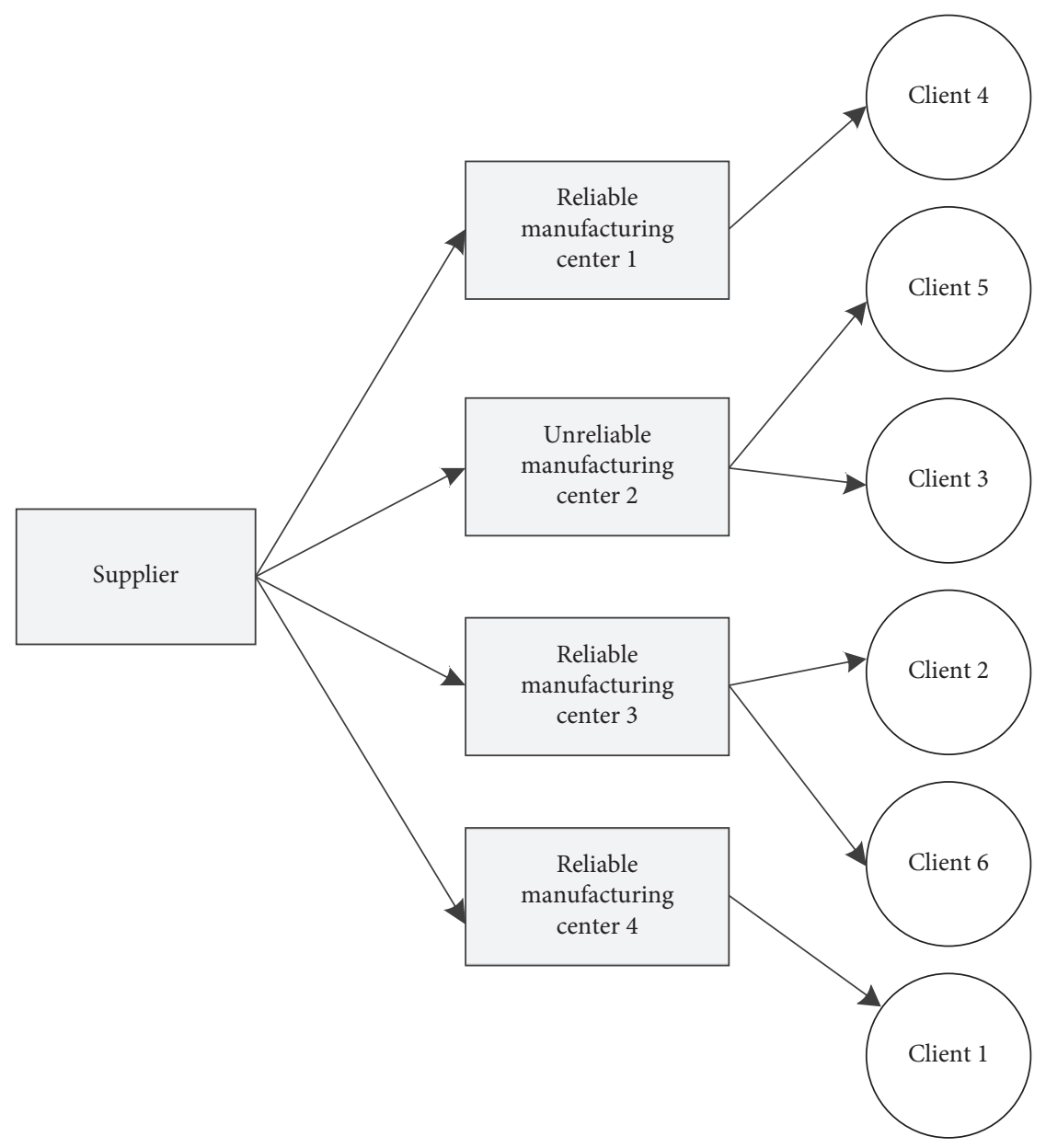

FIgURE 3: Intersite logistics transfer map.

the unreliable manufacturing center 2 is 56.3 , as shown in Figure 3.

Electronic manufacturing companies choose to invest in building manufacturing centers or entrust other foundry companies to make decisions between processing products. When entrusting other processing enterprises to OEM, they will face the interests of other foundry companies, there is a risk of supply interruption, resulting in loss of processing capacity, and the products cannot be delivered on schedule. In order to better analyze the relationship between capacity loss parameters and product cost expenditure, sensitivity analysis of capacity loss and results is performed. The location and quantity of the manufacturing center are determined by changing the capacity loss rate of the unreliable manufacturing center. The total cost, transportation cost, transportation cost, and transshipment amount in the objective function are shown in Table 3.

In the case of overcapacity, the manufacturing center will face the loss of processing capacity. In the face of customer demand uncertainty, the grey theory is used to change the uncertainty problem into the uncertainty probability problem, the transshipment strategy is used to supplement the capacity of unreliable manufacturing center, a three-level supply chain model is established to simulate the market 
TABLE 3: Sensitivity analysis of capacity loss.

\begin{tabular}{|c|c|c|c|c|c|c|c|}
\hline Number & Loss of capacity & Total cost & Central cost & Transportation cost & Transshipment cost & $Y R_{i}$ & $Y U_{i}$ \\
\hline 1 & 0.1 & 138071.3 & 123134.6 & 14924.04 & 12.66 & 4 & $1,2,3$ \\
\hline 2 & 0.15 & 138090.2 & 123134.6 & 14924.04 & 31.56 & 4 & $1,2,3$ \\
\hline 3 & 0.2 & 137975.5 & 123134.6 & 14782.23 & 58.67 & 4 & $1,2,3$ \\
\hline 4 & 0.25 & 138011 & 123134.6 & 14782.23 & 94.17 & 4 & $1,2,3$ \\
\hline 5 & 0.3 & 138054.8 & 123134.6 & 14782.23 & 137.97 & 4 & $1,2,3$ \\
\hline 6 & 0.35 & 138097.7 & 123134.6 & 14782.23 & 180.87 & 4 & $1,2,3$ \\
\hline 7 & 0.4 & 176405.9 & 162413 & 13752.93 & 239.97 & 2,4 & 1,3 \\
\hline 8 & 0.45 & 176453.5 & 162413 & 13752.93 & 287.57 & 2,4 & 1,3 \\
\hline 9 & 0.5 & 176241.5 & 162413 & 13467.33 & 361.17 & 2,4 & 1,3 \\
\hline 10 & 0.55 & 176130.7 & 162413 & 13302.41 & 415.29 & 2,4 & 1,3 \\
\hline 11 & 0.6 & 182986.7 & 169158.2 & 13302.41 & 526.1317 & 1,2 & 3,4 \\
\hline 12 & 0.65 & 216218.8 & 201436.6 & 14782.2 & 0 & $1,2,3$ & - \\
\hline 13 & 0.7 & 216218.8 & 201436.6 & 14782.2 & 0 & $1,2,3$ & - \\
\hline 14 & 0.75 & 216218.8 & 201436.6 & 14782.2 & 0 & $1,2,3$ & - \\
\hline 15 & 0.8 & 216218.8 & 201436.6 & 14782.2 & 0 & $1,2,3$ & - \\
\hline 16 & 0.85 & 216218.8 & 201436.6 & 14782.2 & 0 & $1,2,3$ & - \\
\hline 17 & 0.9 & 216218.8 & 201436.6 & 14782.2 & 0 & $1,2,3$ & - \\
\hline 18 & 0.95 & 216218.8 & 201436.6 & 14782.2 & 0 & $1,2,3$ & - \\
\hline 19 & 1 & 216218.8 & 201436.6 & 14782.2 & 0 & $1,2,3$ & - \\
\hline
\end{tabular}

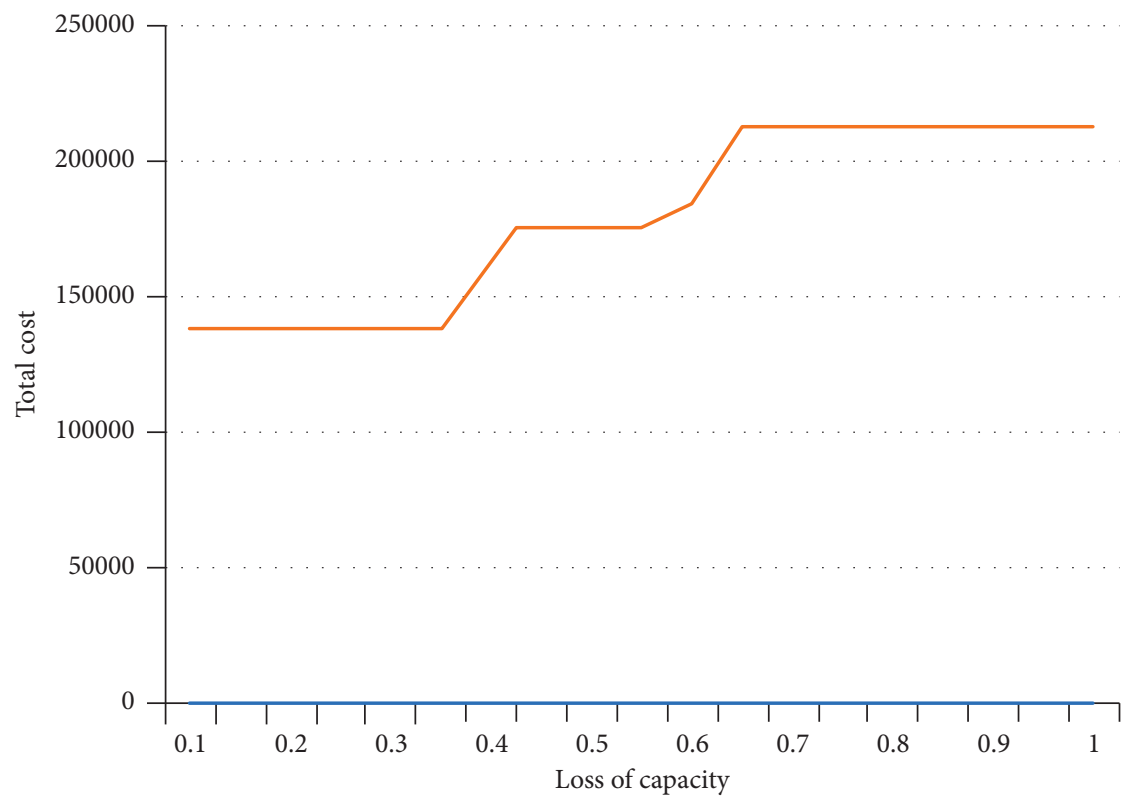

Figure 4: Total cost versus loss of capacity.

operation rules, and the sensitivity analysis of capacity loss to uncertain market demand is conducted. It is found that the greater the capacity loss of unreliable manufacturing center is, it is impossible that the total cost of supply chain and transportation shows an upward trend due to the insufficient operating rate of manufacturing centers. When the capacity loss reaches a certain degree, the manufacturing center with the lowest production capacity will be eliminated, and the overall cost is on the rise.

From the numerical results in columns 2 and 3 of Table 3, it can be concluded that when the capacity loss rate of modern industrial enterprises increases, the total cost of the supply chain shows an upward trend, and the manufacturing center also changes to a reliable manufacturing center (as shown in Figure 4). When the capacity loss reaches 0.65 and above, all manufacturing centers would have been converted into reliable manufacturing centers, and production centers with backward production capacity would have been discontinued.

In order to form the core competitiveness of manufacturing enterprises, it is suggested to develop reliable manufacturing centers as far as possible to cope with the uncertainty of market demand. If the market-oriented OEM manufacturing enterprises can save the construction and management costs of manufacturing centers, the stability of product manufacturing cannot be guaranteed, which may 
cause supply interruption. Therefore, manufacturing enterprises need to build reliable manufacturing centers to ensure the flexibility of the supply chain.

\section{Conclusions}

This paper studies the problem of supply chain disruption in the downstream chain of manufacturing enterprises due to product foundry. The deep reason is that, in the face of risk decision-making, manufacturers will make decisions according to their own interests. This conflict between the manufacturer's interests and the supply chain's interests leads to the risk of disruption, which is more common in daily supply chain operations. When manufacturing companies face the risk of supply disruption, they will not only cause lost production capacity but also even lead to continuous business interruption. In order to solve the downstream supply disruption crisis of manufacturers under uncertain demand, this paper analyses the market elimination mechanism under the condition of product OEM production by constructing the global supply chain of three-level manufacturing enterprises and gives the supply chain elasticity optimization response strategy of manufacturing enterprises. The study found that the development of reliable manufacturing centers can effectively deal with the uncertainty of market demand, while marketoriented product OEMs can save the construction and management costs of manufacturing centers, but the stability of product supply is not stable. To the guarantee, it is likely to cause the risk of supply disruption. Therefore, in order to form the core competitiveness of manufacturing enterprises, the manufacturing supply chain design needs to flexibly select reliable manufacturing centers and unreliable manufacturing centers, reduce the total cost of the supply chain, and ensure the stable operation of the supply chain. In the complex market competition environment, manufacturing enterprises should actively respond, including the supply chain design and the recovery strategy plan after the interruption, so as to form a flexible global supply chain with more risk resistance and improve market competitiveness.

\section{Data Availability}

The data used to support the findings of this study are available from the corresponding author upon request.

\section{Conflicts of Interest}

The authors declare that they have no conflicts of interest.

\section{References}

[1] C. F. Durach, J. Kembro, and A. Wieland, "A new paradigm for systematic literature reviews in supply chain management," Journal of Supply Chain Management, vol. 53, no. 4, pp. 67-85, 2017.

[2] G. Baryannis, S. Validi, S. Dani, and G. Antoniou, "Supply chain risk management and artificial intelligence: state of the art and future research directions," International Journal of Production Research, vol. 57, no. 7, pp. 2179-2202, 2019.

[3] T. J. Pettit, K. L. Croxton, and J. Fiksel, "The evolution of resilience in supply chain management: a retrospective on ensuring supply chain resilience," Journal of Business Logistics, vol. 40, no. 1, pp. 56-65, 2019.

[4] Y. Fan and M. Stevenson, "A review of supply chain risk management: definition, theory, and research agenda," International Journal of Physical Distribution \& Logistics Management, vol. 48, no. 3, pp. 205-230, 2018.

[5] S. Hosseini, N. Morshedlou, D. Ivanov, M. D. Sarder, K. Barker, and A. A. Khaled, "Resilient supplier selection and optimal order allocation under disruption risks," International Journal of Production Economics, vol. 213, pp. 124-137, 2019.

[6] R. Dubey, A. Gunasekaran, S. J. Childe, T. Papadopoulos, C. Blome, and Z. Luo, "Antecedents of resilient supply chains: an empirical study," Institute of Electrical and Electronics Engineers Transactions on Engineering Management, vol. 66, no. 1, pp. 8-19, 2017.

[7] E. Durmić, Ž. Stević, P. Chatterjee, M. Vasiljević, and M. Tomašević, "Sustainable supplier selection using combined FUCOM-Rough SAW model," Reports in Mechanical Engineering, vol. 1, no. 1, pp. 34-43, 2020.

[8] A. Yousefi and M. S. Pishvaee, "A fuzzy optimization approach to integration of physical and financial flows in a global supply chain under exchange rate uncertainty," International Journal of Fuzzy Systems, vol. 20, no. 8, pp. 2415-2439, 2018.

[9] E. Rosca, G. Möllering, A. Rijal, and J. C. Bendul, "Supply chain inclusion in base of the pyramid markets," International Journal of Physical Distribution \& Logistics Management, vol. 49, no. 5, pp. 575-598, 2019.

[10] S. Chakraborty, R. Chattopadhyay, and S. Chakraborty, "An integrated D-MARCOS method for supplier selection in an iron and steel industry," Decision Making: Applications in Management and Engineering, vol. 3, no. 2, pp. 49-69, 2020.

[11] B. Zahiri, J. Zhuang, and M. Mohammadi, "Toward an integrated sustainable-resilient supply chain: a pharmaceutical case study," Transportation Research Part E: Logistics and Transportation Review, vol. 103, pp. 109-142, 2017.

[12] N. Foroozesh, R. Tavakkoli-Moghaddam, S. M. Mousavi, and B. Vahdani, "A new comprehensive possibilistic group decision approach for resilient supplier selection with meanvariance-skewness-kurtosis and asymmetric information under interval-valued fuzzy uncertainty," Neural Computing and Applications, vol. 31, no. 11, pp. 6959-6979, 2019.

[13] A. Haeri, S. M. Hosseini-Motlagh, M. R. Ghatreh Samani, and M. Rezaei, "A mixed resilient-efficient approach toward blood supply chain network design," International Transactions in Operational Research, vol. 27, no. 4, pp. 1962-2001, 2020.

[14] D. Pamucar, M. Yazdani, R. Obradovic, A. Kumar, and M. Torres-Jiménez, "A novel fuzzy hybrid neutrosophic decision-making approach for the resilient supplier selection problem," International Journal of Intelligent Systems, vol. 35, no. 12, pp. 1934-1986, 2020.

[15] H. Golpîra, "Optimal integration of the facility location problem into the multi-project multi-supplier multi-resource construction supply chain network design under the vendor managed inventory strategy," Expert Systems with Applications, vol. 139, p. 112841, 2020.

[16] B. Vishkaei, S. T. A. Niaki, M. Farhangi, and I. Mahdavi, “A single-retailer multi-supplier multi-product inventory model with destructive testing acceptance sampling and inflation," 
Journal of Industrial and Production Engineering, vol. 36, no. 6, pp. 351-361, 2019.

[17] K. J. Mizgier, "Global sensitivity analysis and aggregation of risk in multi-product supply chain networks," International Journal of Production Research, vol. 55, no. 1, pp. 130-144, 2017.

[18] J. Liu, H. Zhou, and J. Wang, "The coordination mechanisms of emergency inventory model under supply disruptions," Soft Computing, vol. 22, no. 16, pp. 5479-5489, 2018.

[19] L. Coleman, "The power of resilience Yossi Sheffi the MIT press, Cambridge MA, 2015, 14 pp," Journal of Contingencies and Crisis Management, vol. 25, no. 2, pp. 114-115, 2017.

[20] B. Niu, J. Li, J. Zhang, H. K. Cheng, and Y. R. Tan, "Strategic analysis of dual sourcing and dual channel with an unreliable alternative supplier," Production and Operations Management, vol. 28, no. 3, pp. 570-587, 2019.

[21] C. Woarawichai and T. Naenna, "Solving inventory lot-sizing with supplier selection under alternative quantity discounts and vehicle capacity," International Journal of Logistics Systems and Management, vol. 30, no. 2, pp. 179-194, 2018.

[22] R. Pellegrino, N. Costantino, and D. Tauro, "Supply chain finance: a supply chain-oriented perspective to mitigate commodity risk and pricing volatility," Journal of Purchasing and Supply Management, vol. 25, no. 2, pp. 118-133, 2019.

[23] A. Qazi, A. Dickson, J. Quigley, and B. Gaudenzi, "Supply chain risk network management: a Bayesian belief network and expected utility based approach for managing supply chain risks," International Journal of Production Economics, vol. 196, pp. 24-42, 2018.

[24] X. Li, J. Chen, and X. Ai, "Contract design in a cross-sales supply chain with demand information asymmetry," European Journal of Operational Research, vol. 275, no. 3, pp. 939-956, 2019.

[25] J. Namdar, X. Li, R. Sawhney, and N. Pradhan, "Supply chain resilience for single and multiple sourcing in the presence of disruption risks," International Journal of Production Research, vol. 56, no. 6, pp. 2339-2360, 2018.

[26] Y. Han, W. K. Chong, and D. Li, "A systematic literature review of the capabilities and performance metrics of supply chain resilience," International Journal of Production Research, vol. 58, no. 15, pp. 4541-4566, 2020.

[27] S. DuHadway, S. Carnovale, and B. Hazen, "Understanding risk management for intentional supply chain disruptions: risk detection, risk mitigation, and risk recovery," Annals of Operations Research, vol. 283, no. 1-2, pp. 179-198, 2019.

[28] H. Shen, Y. Liang, Z.-J. M. Shen, and C.-P. Teo, "Reliable flexibility design of supply chains via extended probabilistic expanders," Production and Operations Management, vol. 28, no. 3, pp. 700-720, 2019.

[29] J. G. Wang, "Research on supply chain location game considering interruption risk," Computer Engineering and Applications, vol. 53, no. 20, pp. 231-236, 2017.

[30] D. Simchi-Levi, H. Wang, and Y. Wei, "Increasing supply chain robustness through process flexibility and inventory," Production and Operations Management, vol. 27, no. 8, pp. 1476-1491, 2018.

[31] R. Sreedevi and H. Saranga, "Uncertainty and supply chain risk: the moderating role of supply chain flexibility in risk mitigation," International Journal of Production Economics, vol. 193, pp. 332-342, 2017.

[32] L. T. T. Doan, Y. Amer, S.-H. Lee, P. N. K. Phuc, and L. Q. Dat, "A comprehensive reverse supply chain model using an interactive fuzzy approach-a case study on the Vietnamese electronics industry," Applied Mathematical Modelling, vol. 76, pp. 87-108, 2019.

[33] L. Jin, R. Mesiar, and R. Yager, "Parameterized preference aggregation operators with improved adjustability," International Journal of General Systems, vol. 49, no. 8, pp. 1-13, 2020.

[34] M. Fattahi and K. Govindan, "A multi-stage stochastic program for the sustainable design of biofuel supply chain networks under biomass supply uncertainty and disruption risk: a real-life case study," Transportation Research Part E: Logistics and Transportation Review, vol. 118, pp. 534-567, 2018.

[35] H. Sun, Q. Y. Cui, and Y. F. Xue, "Research on uncertain demand location-path robust optimization from the perspective of risk coping," Operations Research and Management Science, vol. 26, no. 11, pp. 26-34, 2017.

[36] B. Shen and Q. Li, "Market disruptions in supply chains: a review of operational models," International Transactions in Operational Research, vol. 24, no. 4, pp. 697-711, 2017.

[37] M. R. G. Samani and S.-M. Hosseini-Motlagh, "An enhanced procedure for managing blood supply chain under disruptions and uncertainties," Annals of Operations Research, vol. 283, no. 1-2, pp. 1413-1462, 2019.

[38] S. K. Paul, R. Sarker, and D. Essam, "A reactive mitigation approach for managing supply disruption in a three-tier supply chain," Journal of Intelligent Manufacturing, vol. 29, no. 7, pp. 1581-1597, 2018.

[39] L. M. Maiyar and J. J. Thakkar, "Robust optimisation of sustainable food grain transportation with uncertain supply and intentional disruptions," International Journal of Production Research, vol. 58, no. 18, pp. 5651-5675, 2020.

[40] B. C. Giri and S. Dey, "Game theoretic models for a closed-loop supply chain with stochastic demand and backup supplier under dual channel recycling," Decision Making: Applications in Management and Engineering, vol. 3, no. 1, pp. 108-125, 2020.

[41] A. Qamar, M. A. Hall, D. Chicksand, and S. Collinson, "Quality and flexibility performance trade-offs between lean and agile manufacturing firms in the automotive industry," Production Planning \& Control, vol. 31, no. 9, pp. 723-738, 2020.

[42] J. Hong, Y. Zhang, and M. Ding, "Sustainable supply chain management practices, supply chain dynamic capabilities, and enterprise performance," Journal of Cleaner Production, vol. 172, pp. 3508-3519, 2018.

[43] A. Shishodia, P. Verma, and V. Dixit, "Supplier evaluation for resilient project driven supply chain," Computers \& Industrial Engineering, vol. 129, pp. 465-478, 2019.

[44] M. Yazdani, C. Kahraman, P. Zarate, and S. C. Onar, "A fuzzy multi attribute decision framework with integration of QFD and grey relational analysis," Expert Systems with Applications, vol. 115, pp. 474-485, 2019.

[45] Z. Rezaee, "Supply chain management and business sustainability synergy: a theoretical and integrated perspective," Sustainability, vol. 10, no. 1, p. 275, 2018.

[46] B. Liu and K. Iwamura, "Chance constrained programming with fuzzy parameters," Fuzzy Sets and Systems, vol. 94, no. 2, pp. 227-237, 1998.

[47] B. Kim and K. S. Park, "Organizational structure of a global supply chain in the presence of a gray market: information asymmetry and valuation difference," International Journal of Production Economics, vol. 175, pp. 71-80, 2016. 